\title{
"IMIGRANTES" VERSUS "NATIVOS" DIGITAIS: O DISCURSO DE TECNOLOGIAS DIGITAIS EM POLÍTICAS CURRICULARES
}

\author{
DIGITAL “IMMIGRANTS” VERSUS “NATIVE”: DISCOURSE OF \\ DIGITAL TECHNOLOGIES IN CURRICULUM POLICIES
}

\section{“INMIGRANTES” VERSUS “NATIVOS” DIGITALES: EL DISCURSO DE TECNOLOGÍAS DIGITALES EN POLÍTICAS CURRICULARES}

\author{
Carla Cristiane Loureiro* \\ Professora do Colégio de Aplicação da Universidade Federal de Santa Catarina \\ Viviane Grimm** \\ Professora do Instituto Federal de Santa Catarina - Jaraguá do Sul \\ Geovana Mendonça Lunardi Mendes ${ }^{* * * *}$ \\ Professora do Programa de Pós-Graduação em Educação da Universidade do Estado de Santa \\ Catarina
}

Resumo: Os discursos de "nativo digital" e "imigrante digital" em políticas curriculares são objeto central de análise neste artigo. Buscou-se refletir sobre as relações entre docência, criança, infância, tecnologia e currículo, utilizando-se como material empírico alguns documentos curriculares elaborados pelo Governo Federal brasileiro a partir dos anos 2000. A partir da pesquisa, observou-se que o lugar social da criança na relação com as tecnologias digitais é marcado pela existência de uma "expertise" garantida por uma "experiência geracional inata" (criança-nativos) em contraposição às demais gerações (docentes-imigrantes), apontando uma visão naturalizada e determinista sobre a tecnologia em detrimento a usos mais significativos e possibilidades de empoderamento de professores e crianças.

Palavras-chave: Crianças. Professores. Tecnologias digitais. Currículo.

\footnotetext{
* Mestre em Educação pela Universidade Federal de Santa Catarina; doutoranda em Educação pela Universidade Estadual de Santa Catarina.

** Mestre em Educação pela Universidade Regional de Blumenau; doutoranda em Educação pela Universidade Estadual de Santa Catarina.

*** Doutora em Educação pela Pontifícia Universidade Católica de São Paulo; Mestre em Educação pela Universidade Federal de Santa Catarina.
} 
Abstract: The discourses of "digital native" and "digital immigrant" in curriculum policies are the central object in analysis of this article. Its aim was to reflect on the relations between teaching, child, childhood, technology and curriculum, using as empirical material some curriculum documents written by the Brazilian Federal Government from the year 2000. It is considered that the child's social place in relation with digital technologies is marked by the existence of an "expertise" guaranteed by an "innate generational experience" (child-natives) in contrast to the other generations (teachers-immigrants), indicating a naturalized and deterministic view of the technology to the detriment of more significant uses and empowerment possibilities of teachers and children.

Keywords: Children. Teachers. Digital technologies. Curriculum.

Resumen: Los discursos de "nativo digital" e "inmigrante digital" en las políticas curriculares son objeto central de análisis de este artículo. Su objetivo es reflexionar sobre la relación entre docencia, niño, infancia, tecnología y plan de estudios, utilizando como material empírico algunos documentos curriculares elaborados por el gobierno federal de Brasil desde los años 2000. Se considera que el lugar social del niño en relación con las tecnologías digitales es marcado por la existencia de una "expertise" garantizada por una "experiencia generacional innata" (niño-nativos) en contraste con las otras generaciones (maestros-inmigrantes), indicando un punto de vista naturalizado y determinista de la tecnología en detrimento de usos más significativos y posibilidades de empoderamiento para los maestros y los niños.

Palabras clave: Niños. Maestros. Tecnologías digitales. Currículo.

\section{ARGUMENTOS INICIAIS}

Ao longo das últimas três décadas, tem-se presenciado um conjunto de políticas educacionais que buscam a inclusão de tecnologias digitais (TD) ${ }^{1}$ nas escolas públicas de diferentes países latino-americanos. No Brasil, em especial, o Governo tem elaborado políticas e programas educacionais, desde meados dos anos 1980, que visam dotar as escolas de laboratórios de informática, TVs, kits de vídeos e, mais recentemente, notebooks, computadores, tablets e rede de internet.

Nesse contexto, os discursos sobre TD têm sido incorporados ao discurso pedagógico sob o prisma de "renovação educacional", considerando as tecnologias como item indispensável para solucionar os mais diversos problemas educacionais, 
como a melhoria no rendimento de estudantes, o fracasso escolar e o desinteresse, até questões de cunho socioeconômico, como a inserção dos países subdesenvolvidos no mercado globalizado e a melhoria da competitividade econômica dessas nações, ou a solução para os conflitos geracionais, nativos versus imigrantes digitais (PRENSKY, 2001), ancorando-se na ideia de que a escola precisa se modernizar para responder aos desafios postos pelos modos de vida da modernidade, da cultura digital, da globalização, da sociedade do conhecimento, da sociedade em rede, da sociedade da informação, etc.

Esses discursos sobre as TD na educação têm atravessado diferentes esferas do campo social. Eles têm sido apropriados, sobretudo, em documentos curriculares oficiais, que naturalizam um conjunto de visões sobre docência, criança, infância, currículo e tecnologias. Neles, tem chamado a atenção o uso generalizado e naturalizado das categorias "imigrante digital" e "nativo digital", ambos utilizados para qualificar a relação entre professores e crianças quando o assunto são TD.

Considera-se, nesta pesquisa, que tais categorias são insuficientes e limitadas para se compreenderem as complexas relações entre sociedade, indivíduo e tecnologia. Trata-se de uma compreensão que tende a responsabilizar as crianças e os jovens pela iniciativa e pelo dinamismo no uso das tecnologias, desconsiderando o que podem fazer os adultos para proporcionar usos mais ricos e desafiantes destas, além de não considerar que as experiências que as crianças e os jovens têm com as tecnologias são fortemente marcadas pelo nível socioeconômico e pelo capital cultural (DUSSEL, 2012).

Partindo desse enquadramento, neste artigo busca-se problematizar os discursos de "nativo digital" e "imigrante digital" apropriados nos documentos curriculares oficiais elaborados pelo Governo Federal brasileiro. De modo mais específico, busca-se refletir sobre as relações entre docência, criança, infância, tecnologia e currículo, a partir da análise dos discursos sobre TD presentes nos seguintes documentos: Parecer do CNE/CP n. 9/2001 e Resolução CNE/CP n. 1/2002 - Diretrizes Curriculares Nacionais para a Formação de Professores da Educação Básica -, bem como nas Diretrizes Curriculares Nacionais Gerais para a Educação Básica de 2013. Optou-se por utilizar as políticas curriculares oficiais como fonte de investigação pelo fato de considerar que o Estado brasileiro ocupa uma posição privilegiada, isto é, conhecida, reconhecida e legítima no processo de produção, de divulgação e de circulação de discursos pedagógicos e proposições curriculares. Nesta pesquisa, entendem-se as políticas curriculares como um espaço de "ação simbólica" e de recontextualização de discursos pedagógicos (BERNSTEIN, 1996), fruto de polêmicas, de decisões con- 
tínuas, dos confrontos entre os diferentes projetos culturais, sociais e econômicos em disputa (PACHECO, 2003), construídas em um processo cíclico, marcado por lutas entre projetos sociais com interesses antagônicos, que emergem de uma contínua interação entre contextos, textos, discursos e práticas (BALL, 1997).

Assim, considerando que os discursos pedagógicos sobre TD são recontextualizados por meio de disputas entre os diferentes agentes e/ou instituições do campo educacional, parte-se do pressuposto de que os discursos pedagógicos sobre TD tendem a apresentar professores e crianças em oposição, que, por sua vez, tem contribuído para legitimar um imaginado professor em situação de atraso ao seu tempo, assim como parecem reafirmar pressupostos essencialistas e deterministas sobre a infância e a tecnologia.

Nas seções a seguir, abordam-se, inicialmente, algumas premissas teóricas sobre infância, tecnologia e docência que ancoram a pesquisa. Na sequência, faz-se uma síntese dos discursos sobre TD nas políticas curriculares analisadas na pesquisa. Por fim, encerra-se o texto com algumas reflexões sobre as implicações das categorias "imigrante digital" e "nativo digital" no modo de compreender as relações entre infância, docência e TD.

\section{ALGUMAS NOTAS SOBRE INFÂNCIA, DOCÊNCIA E TECNOLOGIA}

Ao final do século XX e início do XXI, a ideia que parece vigorar com força entre os diversos pensadores sobre a infância é a de que esta é uma "construção social" (SARMENTO; PINTO, 1997; PINTO, 1997; SIROTA, 2001; MONTANDON, 2001). Tal ideia traz em seu bojo, a partir de uma "nova" perspectiva, a consideração de que a criança é também sujeito de direitos, exercitando, assim, os primeiros passos pela emancipação da condição de sujeito silenciado da e na história.

Apesar dessas discussões, a construção histórica da infância tem sido realizada por meio da exclusão das crianças dos espaços sociais de influência, confinando-as a um espaço social condicionado e controlado pelos adultos, em especial a escola, que, no desenvolvimento da sociedade moderna, converte-se na forma principal e dominante de educação para crianças e para formação de novas gerações. Com isso, a escola passa a ser a instituição com ligação mais íntima com uma concepção de infância formulada em determinado tempo histórico. Segundo Sarmento (2002, p. 11), “[...] a construção histórica da infância foi o resultado de um processo complexo de produ- 
ção de representações sobre a criança, de estruturação de seus quotidianos e mundos de vida e, especialmente, de constituição de organizações sociais para as crianças."

A partir do campo de estudos da infância, opera-se com a premissa de que infância e escolarização são conceitos que se constroem reciprocamente. Desse modo, considera-se que os documentos curriculares apresentam possibilidades de vislumbrar os discursos que acabam por produzir e reproduzir as ideias de infância, professor e docência em meio às disputas que marcam a produção de tais textos.

Paralelamente e em confluência com os estudos sobre infância, tem-se intensificado, nas últimas décadas, pesquisas que buscam entender a relação da criança com as TD, quase sempre sob a perspectiva adulta dessa relação. Já não é mais possível negar a presença das tecnologias na vida das crianças, e, nesse sentido, deve-se atentar para as implicações da própria concepção de infância e do conceito de criança em nosso tempo.

Apesar da aparente centralidade da criança na escola, muitas vezes, elas parecem invisíveis aos formuladores de políticas. Tal invisibilidade corresponde à certa ausência de avaliação dos impactos de formulações de políticas sobre diferentes gerações, especialmente sobre as crianças. A infância não é uma fase transitória, o que é transitório são seus sujeitos (crianças); assim, qualquer medida da política afeta diferenciadamente as várias gerações (QVORTRUP, 2010a, 2010b). Tais impactos podem ser claramente percebidos na escola, que corresponde à institucionalização histórica de processos de disciplinarização da infância (FOUCAULT, 1993), configurando-se uma arena de conflitos para projetos políticos e pedagógicos que tanto podem se orientar para uma defesa da ampliação dos direitos das crianças quanto promoverem práticas assentadas na dominação.

Não há dúvidas quanto à importância que exercem as TD na definição das culturas das crianças hoje em dia. Segundo o relatório TICs Crianças 2010 (COMITÊ GESTOR DA INTERNET NO BRASIL, 2012), ${ }^{2} 51 \%$ das crianças brasileiras afirmam já ter utilizado o computador pelo menos uma vez. Outro dado significativo apresentado no relatório da pesquisa TIC Kids Online Brasil 2012 (COMITÊ GESTOR DA INTERNET NO BRASIL, 2013)3 aponta que, no Brasil, a maioria (58\%) dos jovens usuários de internet, entre 9 e 16 anos, acessa-a em seus domicílios, e em segundo lugar aparece a escola, citada por $42 \%$ dos entrevistados.

O mesmo relatório, em 2013, aponta que utilizar a internet para fins escolares, por exemplo, é a atividade mais comumente mencionada pelas crianças: 87\% dos usuários com idades entre 9 e 17 anos afirmam acessar a rede com essa finalidade. Também se destaca o fato de $49 \%$ das crianças e dos jovens afirmarem que recebem 
conselhos dos professores sobre o uso seguro da internet (COMITÊ GESTOR DA INTERNET NO BRASIL, 2014).

Nesse cenário, os professores são constantemente considerados “despreparados" no que se refere aos usos das TD, sendo classificados, de acordo com algumas perspectivas teóricas, como "imigrantes virtuais" e culpabilizados pelas expectativas não atendidas de melhoria da educação por meio do uso das tecnologias no contexto escolar, reforçando, assim, o sentimento de "mal-estar" entre os docentes (ESTEVES, 1999). A escola e, mais particularmente, os professores sentem que têm falhado no cumprimento de sua "missão", contribuindo para a imagem dos professores como um grupo profissional "desajustado" ao seu tempo, em virtude das mudanças de um mundo globalizado.

Barreto (2004) observa a existência de um atravessamento do uso das TD nas políticas educacionais e nos processos de formação dos professores, bem como uma expressiva quantidade de estudos que tentam redefinir o status da profissão de professor, sugestionando formas que possam superar o modelo de aprendizagem receptiva em prol de um profissional que trabalhe em rede e incorpore as tecnologias no seu fazer pedagógico. No entanto, essas políticas e muitos desses estudos, de acordo com a autora, partilham da visão, de maneira implícita ou explícita, de "educação como mercadoria", desconsiderando os determinantes históricos e sociais da escola, bem como a luta daqueles que defendem a "educação como direito e prática emancipatória".

Neste artigo, considera-se que os discursos pedagógicos sobre TD presentes nas políticas curriculares buscam gerar novas disposições docentes, nesse caso, que professores sejam aptos no manuseio das TD e na sua inserção no processo de ensino e aprendizagem. Esses discursos, quando tomados no contexto dos discursos pedagógicos oficiais, não prescrevem apenas um conjunto de disposições, mas exercem influência sobre os sentidos do que é ser professor na contemporaneidade. Os discursos pedagógicos sobre TD, constantemente associados às ideias de "modernização", atribuem ao professor um lugar de desprestígio, desconsiderando-se os condicionantes que envolvem o contexto educacional e mostrando uma perspectiva de "superioridade" das tecnologias, reduzindo o próprio conceito de tecnologia apenas a sua dimensão instrumental.

Essa forma de incorporação das tecnologias no discurso pedagógico parece ter como principal característica a ausência de historicidade, evidenciada pelo excesso de presentismo e impressionismo, conforme observa Vieira Pinto (2005) diante da ideia de vivermos uma "explosão tecnológica" ou "era tecnológica". Para o autor, diante do 
aparato tecnológico de seu tempo, em uma concepção ingênua de tecnologia, as pessoas tornam-se incapazes de situar um fato no processo que as engendra, ignorando as conexões históricas e impossibilitando avaliar as situações passadas que não assistiram, impressionando-se pela ideia de superioridade da situação atual, em que

[...] não percebendo os condicionantes históricos que a explicam, queda-se embasbacada diante de tremenda multiplicação de fatos e produtos tecnológicos em que agora se acha envolvida a existência humana, e proclama, com plena candura de espírito, estarmos vivendo uma época excepcional, caracterizada pela assombrosa "explosão tecnológica" que engloba a vida da humanidade, a ponto de modificá-la em todas as suas manifestações [...] (VIEIRA PINTO, 2005, p. 233).

Nesse sentido, a tecnologia é tomada como instrumento e também panaceia, e, dessa forma, tem-se a percepção de ser ela produtora do humano e não produto do ser humano, o que Vieira Pinto (2005) denominou ideologização da tecnologia (tecnocentrismo). Tais ideias parecem assumir uma dimensão fundamental para o campo educacional, que tem se apresentado como fértil para adaptações passivas e acríticas de projetos de inserção de tecnologias na escola, as quais, muitas vezes, em vez de meios, tornam-se fins da educação.

Outra questão fundamental para professores e crianças é o reconhecimento de que há um diálogo difícil entre a cultura digital e a cultura da escola. A primeira que exige um lugar social do sujeito como colaborativo que experimenta novos modos de autoria, subjetivação e de sociabilidade, e a segunda que coloca o sujeito no papel de aluno "[...] destinatário da acção adulta, agente de comportamentos prescritos, pelo qual é avaliado, premiado ou sancionado.” (SARMENTO, 2011, p. 588).

Essas formas de compreender as TD no campo educacional têm dificultado uma análise mais aprofundada acerca das formas que as crianças e os professores constroem suas aprendizagens na relação com as TD. Além disso, temos também que considerar que relações mais ativas e participativas não "brotarão" por conta própria ou pelo simples contato das crianças com as tecnologias digitais. Devemos considerar, portanto, uma outra forma de compreender suas relações com as TD, considerando as crianças e os professores como atores sociais em que as crianças constroem formas culturais radicadas e desenvolvidas historicamente em "[...] modos específicos de comunicação intrageracional e intergeracional.” (SARMENTO, 2002, p. 21). 


\section{POLÍTICAS CURRICULARES E TD: O QUE PRESCREVEM OS DOCUMENTOS?}

Neste trabalho, toma-se como objeto de reflexão o Parecer do CNE/CP n. 9/2001 e a Resolução CNE/CP n. 1/2002 - Diretrizes Curriculares Nacionais para a Formação de Professores da Educação Básica $-{ }^{4}$ bem como as Diretrizes Curriculares Nacionais Gerais para a Educação Básica de 2013. Esses documentos foram selecionados pelo fato de terem norteado os projetos de curso de formação inicial e continuada de professores até o ano 2015, como também o que as redes de ensino, escolas e professores devem privilegiar na organização de seus projetos educativos, nos diferentes níveis de ensino da Educação Básica. Além disso, são documentos construídos no âmbito do Conselho Nacional de Educação com a participação de diversas instituições representativas, em que concepções sobre educação, escola, docência e currículo estão em enfrentamento.

Em documentos que expressam as políticas curriculares no Brasil, práticas discursivas sobre as TD são mobilizadas de modo parecido em diferentes textos. Nas Diretrizes para Formação de Professores, os saberes relacionados à TD foram incorporados como prioridade, e sua presença nos projetos de curso é exigência legal desde 2002. No Art. $2^{\circ}$, inciso VI, determina-se que a organização curricular de cada instituição deverá observar outras formas de orientação inerentes à formação para a atividade docente, entre as quais o preparo para "[...] o uso de tecnologias da informação e da comunicação e de metodologias, estratégias e materiais de apoio inovadores." (BRASIL, 2002, p. 31).

Essas diretrizes fundamentaram-se nos Pareceres CNE/CP n. 9/2001 e n. 27/2001, que apresentaram um amplo conjunto de ideias e premissas sobre formação de professores. O Parecer do CNE/CP n. 9/2001, ao construir um panorama das questões a serem enfrentadas na formação de professores, dedica um subtítulo exclusivo para tratar da "[...] ausência de conteúdos relativos às tecnologias da informação e das comunicações." (BRASIL, 2001, p. 24). O texto parte da constatação de que, se o uso das novas TIC é considerado um recurso importante para a Educação Básica, o “[...] mesmo deve valer para a formação de professores.” No entanto, ressalta a baixa oportunidade que os futuros professores têm de aprender a usar equipamentos ou de desenvolver os conteúdos curriculares com o uso de diferentes tecnologias, destacando que os cursos presos às formas tradicionais reforçam atitudes de resistência ao uso das TIC, resultado da "[...] insegurança que sentem os formadores e seus alunos-professores [...]" (BRASIL, 2001, p. 25), indo na “[...] contramão do desenvolvimento 
tecnológico da sociedade contemporânea [...]" (BRASIL, 2001, p. 25). Nesse sentido, o texto finaliza ressaltando que:

[...] urge inserir as diversas tecnologias da informação e das comunicações no desenvolvimento dos cursos de formação de professores [...] [e prepará-los para] [...] a gestão e a definição de referências éticas, científicas e estéticas para a troca e negociação de sentido, que acontece especialmente na interação e no trabalho escolar coletivo [...] em ambientes reais e virtuais. (BRASIL, 2001, p. 25).

Desse modo, pode-se observar que o documento ressalta a positividade das TIC como forma de a escola conseguir se adequar à sociedade contemporânea, marcada pelo advento das comunicações em massa e das tecnologias digitais, bem como ressalta o atraso dos cursos de formação de professores em relação à incapacidade de adequarem-se a este novo tempo. "[...] os cursos ainda não sabem preparar professores que vão exercer o magistério nas próximas duas décadas, quando a mediação da tecnologia vai ampliar e diversificar as formas de interagir e compartilhar, em tempos e espaços nunca antes imaginados." (BRASIL, 2001, p. 25).

Práticas discursivas que atrelam inovação educacional e tecnologia, como forma de manter a escola em sintonia com as demandas da sociedade contemporânea, também são privilegiadas nas Diretrizes Nacionais Gerais para a Educação Básica. Trata-se de um documento que busca, de partida, servir para a "[...] reinvenção da educação brasileira" colocando-se a serviço da "[...] construção de uma Nação cada vez mais justa, solidária e capaz de desenvolver todas as suas inúmeras potencialidades." (BRASIL, 2013, p. 4). Discursos sobre TD permeiam diversas partes do documento, apresentando-se como um imperativo aos diferentes níveis da Educação Básica, como elemento de organização curricular:

[...] a base comum nacional e a parte diversificada são organizadas e geridas de tal modo que também as tecnologias de informação e comunicação perpassem transversalmente a proposta curricular desde a Educação Infantil até o Ensino Médio, imprimindo direção aos projetos político-pedagógicos. (BRASIL, 2013, p. 33).

Como recurso metodológico:

[...] compreender os efeitos da "infoera", sabendo que estes atuam, cada vez mais, na vida das crianças, dos adolescentes e adultos, para que se reconheçam, de um lado, os estudantes, de outro, os profissionais da educação e a família, mas reconhecendo que os recursos midiáticos devem permear todas as atividades de aprendizagem [...] a utilização de novas mídias e 
tecnologias educacionais, como processo de dinamização dos ambientes de aprendizagem. (BRASIL, 2013, p. 33, 50).

Como forma de acesso ao conhecimento e inclusão digital:

[...] a infraestrutura tecnológica, como apoio pedagógico às atividades escolares, deve também garantir acesso dos estudantes à biblioteca, ao rádio, à televisão, à internet aberta às possibilidades da convergência digital [...] utilização qualificada das tecnologias e conteúdos das mídias como recurso aliado ao desenvolvimento do currículo contribui para o importante papel que tem a escola como ambiente de inclusão digital e de utilização crítica das tecnologias da informação e comunicação [...] (BRASIL, 2013, p. 25, 136).

Ou, ainda, como item indispensável na formação de professores:

[...] (projetos políticos pedagógicos) preveja formação continuada dos gestores e professores para que estes tenham a oportunidade de se manter atualizados quanto ao campo do conhecimento que lhes cabe manejar, trabalhar e quanto à adoção, à opção da metodologia didático-pedagógica mais própria às aprendizagens que devem vivenciar e estimular, incluindo aquelas pertinentes às Tecnologias de Informação e Comunicação (TIC) [...] é preciso que se ofereça aos professores formação adequada para o uso das tecnologias da informação e comunicação e que seja assegurada a provisão de recursos midiáticos atualizados e em número suficiente para os alunos. (BRASIL, 2013, p. 49, 111).

Os excertos anteriores, retirados entre diversos outros, mostram a diversidade dos discursos sobre TD, relacionados a diferentes dimensões do contexto escolar que, direta ou indiretamente, impactam no conjunto de atividades que o professor exerce. No documento, o professor é descrito em uma posição de resistência às TD, apego ao passado e defasagem em relação às capacidades digitais, conforme excerto a seguir:

[...] a escola se prende às características de metodologias tradicionais, com relação ao ensino e à aprendizagem como ações concebidas separadamente, as características de seus estudantes requerem outros processos e procedimentos [...] Os estudantes, entre outras características, aprendem a receber informação com rapidez, gostam do processo paralelo, de realizar várias tarefas ao mesmo tempo, preferem fazer seus gráficos antes de ler o texto [...], os docentes creem que acompanham a era digital apenas porque digitam e imprimem textos, têm e-mail, não percebendo que os estudantes nasceram na era digital. (BRASIL, 2001, p. 25). 
A forma como os estudantes e os professores pretensamente lidam com as TD é incorporada ao discurso das políticas curriculares a partir da lógica de oposição binária entre o "imigrante" versus o "nativo", o "novo" versus o "velho", o "artificial" versus o "natural". As TD são apresentadas ora como ferramenta, ora como panaceia para a escola, capaz de promover "novos métodos didático-pedagógicos", garantindo acesso ao saber. Parecem um tipo de "futuro do presente" em que "[...] utopias educacionais parecem ser suportadas pelo estímulo ao uso pedagógico de tecnologias da informação e comunicação na escola, assim como por estratégias governamentais que delas se valem para mediar nossas ansiedades contemporâneas por tudo digitalizar." (SOSSAI; SILVA; LUNARDI-MENDES, 2012, p. 74).

$\mathrm{O}$ discurso sobre a inserção das TD, que atravessam os textos das políticas curriculares analisadas, parte de imagens sobre o perfil da criança e do jovem (digital) em oposição ao perfil dos professores (analógico), demarcando o fato de aqueles "nascerem na era digital", em oposição a seus professores, que somente "creem que acompanham a era digital". De acordo com as diretrizes curriculares analisadas, "[...] essa distância necessita ser superada, mediante aproximação dos recursos tecnológicos de informação e comunicação, estimulando a criação de novos métodos didático-pedagógicos [...]" (BRASIL, 2013, p. 25-26). Ou, ainda, afirma-se que "[...] hoje, exige-se do professor mais do que um conjunto de habilidades cognitivas, sobretudo se ainda for considerada a lógica própria do mundo digital e das mídias em geral, o que pressupõe aprender a lidar com os nativos digitais [...]” (BRASIL, 2013, p. 59).

Tais argumentos têm sido utilizados, amplamente, como uma das explicações para justificar as dificuldades de inserção das tecnologias na escola. Nesse sentido, surgem no campo algumas categorias para compreender o lugar das crianças nas relações com as tecnologias digitais. Uma dessas categorias mobilizadas é o "nativo digital", usado para definir os nascidos imersos nas tecnologias (PRENSKY, 2001). O uso da expressão "nativos digitais", de forma genérica, aparenta desconsiderar a existência de, no mínimo, dois níveis de "divisão digital": uma relacionada ao acesso às tecnologias a partir da posse e da frequência de uso e a outra relacionada aos usos e às habilidades que pressupõem (PONTE; SIMÕES, 2013). Assim, “[ [...] se o acesso corresponde à condição básica e necessária para se pensar a inclusão digital, não é suficiente para garantir igualdade de oportunidades perante as tecnologias que se dispõe." (PONTE; SIMÕES, 2013, p. 28).

Nesse sentido, deve-se ficar atento às diferenças na qualidade do uso da tecnologia pelas crianças e pelos jovens, bem como à importância de não confundir acesso à tecnologia com uso significativo da tecnologia, aumento da agência e empo- 
deramento dos usuários. Além disso, as Diretrizes alertam para as singularidades das crianças e dos jovens atendidos pela Educação Básica:

[...] é importante considerar os dizeres de Narodowski (1998). Ele entende, apropriadamente, que a escola convive hoje com estudantes de uma infância, de uma juventude (des)realizada, que estão nas ruas, em situação de risco e exploração, e aqueles de uma infância e juventude (hiper) realizada com pleno domínio tecnológico da internet, do orkut, dos chats. Não há mais como tratar: os estudantes como se fossem homogêneos, submissos, sem voz [...] (BRASIL, 2013, p. 35).

Contudo, ao mesmo tempo que apresentam tais singularidades, a forma como as diretrizes abordam a "inclusão digital", como se fosse algo espontâneo e que pode ser induzido pela oferta de computadores e acesso à internet, apresenta, a partir das narrativas em torno da categoria "nativo digital", um conjunto de pressupostos essencialistas sobre crianças e tecnologia, em que as crianças são vistas como se nascessem "tecnicamente qualificadas" para lidar com as TD, sem reconhecer as experiências vividas. Apresenta, também, uma visão determinista sobre a tecnologia, como se esta fosse dotada de uma série de qualidades que impactam (para melhor ou pior) as crianças, independentemente do contexto em que estão inseridas (SELWYN, 2009), conforme pode-se observar no excerto a seguir:

Novos desafios se colocam, pois, para a escola, que também cumpre um papel importante de inclusão digital dos alunos. Ela precisa valer-se desses recursos e, na medida de suas possibilidades, submetê-los aos seus propósitos educativos. Há que se considerar que a multiplicação dos meios de comunicação e informação nas sociedades de mercado em que vivemos contribui fortemente para disseminar entre as crianças, jovens e população em geral o excessivo apelo ao consumo e uma visão de mundo fragmentada, que induz à banalização dos acontecimentos e à indiferença quanto aos problemas humanos e sociais. É importante que a escola contribua para transformar os alunos em consumidores críticos dos produtos oferecidos por esses meios, ao mesmo tempo em que se vale dos recursos midiáticos como instrumentos relevantes no processo de aprendizagem, o que também pode favorecer o diálogo e a comunicação entre professores e alunos. (BRASIL, 2013, p. 111).

Novamente, depara-se com a negação da singularidade das crianças e dos jovens para apresentar a outra faceta das noções de infância que o documento apresenta. Assim, elas são vistas como vítimas de uma forma potente e altamente manipulativa de cultura de consumidor, à qual é quase impossível resistir. Isso não significa que estejamos negando o poder considerável do mercado em determinar os significados e 
os prazeres disponíveis; mas, ao apresentar a escola como o agente "[...] para transformar os alunos em consumidores críticos dos produtos oferecidos por esses meios" (BRASIL, 2013, p. 111), o documento parece não considerar que as “[...] próprias crianças exercem um papel fundamental na criação desses significados e prazeres, e elas podem defini-los e se apropriar deles de diferentes maneiras." (BUCKINGHAM, 2012, p. 68).

Além disso, é necessário atentar ao fato de que nem todas as crianças e os jovens têm a mesma capacidade de acessar os bens de consumo, uma vez que esse acesso não depende somente de vontade, mas também dos recursos materiais. “[...] o mercado não é um mecanismo neutro, e a provisão marketizada de bens e serviços (inclusive na mídia e na educação) pode exacerbar as desigualdades existentes." (BUCKINGHAM, 2012, p. 67).

\section{AFINAL, IMIGRANTES, NATIVOS OU EXCLUÍDOS DIGITAIS?}

No campo educacional, diferentes recursos de tecnologias de informação e comunicação vêm adentrando a escola e as políticas educacionais desde meados do século XX, como meios para qualificação da escola e do professor, reatualizando “[...] práticas discursivas e políticas que nos últimos dois séculos têm reincididamente vinculado a adoção de novas tecnologias e materiais escolares a proposições de renovação educacional." (SOUZA, 2013, p. 104).

Nos documentos analisados, observaram-se discursos relacionados às TD que enfatizam a necessidade de renovação da escola, de sua modernização, justificada na ideia de que vivemos na "sociedade de informação" e suas derivações, apresentada de modo "positivado" e "naturalizado", com nenhum ou pouco questionamento crítico e marcado por "presentismo" e "impressionismo" na forma de compreender a relação entre os indivíduos e as tecnologias, cujos sentidos agenciados no campo da docência desdobram-se em uma imaginada "performance-docente-tecnológica", capaz de assegurar professores suficientemente habilidosos para garantir o bom andamento da escola, ao mesmo tempo que os coloca em uma situação de desprestígio, por estar em atraso ou em dívida com o tempo das crianças, supostamente o tempo digital.

Os discursos sobre TD associados às crianças e aos jovens presentes nos documentos analisados deixam entrever duas tendências sobre o lugar social da criança na relação com as TD: a primeira indica uma expertise "inata" no modo como as crianças lidam com as diversas tecnologias, associando essa "habilidade natural" 
a uma experiência geracional, apesar de ainda inscrita apenas a questão técnica. A segunda tendência, de certa forma, ampara-se na primeira, visto que, se a criança é apenas "tecnicamente competente" no uso das tecnologias digitais, ela está em risco, uma vez que a internet não é considerada um ambiente seguro para ela, cabendo aos adultos protegê-la.

Dessa forma, políticas curriculares que buscam a "inclusão digital", o que aparece nos documentos oficiais como um dos objetivos associados às TD na educação, engendram um discurso que parece ignorar a diferença, mesmo defendendo a inclusão. À medida que esse discurso idealiza o "nativo digital", provoca exclusões, entendendo-o como o portador de algo que os outros, os "excluídos digitais", não possuem. Tal discurso proporciona uma espécie de concepção dominante sobre o que é legítimo e esperado das crianças na sua relação com as tecnologias, isto é, o "normal" é ser "nativo digital". Desse modo, as "[...] práticas e concepções de crianças que se afastam da normatividade definida pelas classes e grupos sociais dominantes podem levar a excluir essas crianças do próprio estatuto social reconhecido da infância: tematizados como 'não-crianças' [...]” (SARMENTO, 2011, p. 585).

Além disso, cabe questionar o interesse advindo de um mercado de produtos lucrativos com a entrada do computador na escola, a individualização do ensino por meio de material instrucional padronizado, bem como o fetiche de uma comunicação irrestrita e sem controle, desconsiderando que aquilo que à primeira vista parece ser mais democrático no acesso à informação na rede, menos hierárquico que o saber erudito ou científico, reintroduz novas formas de verticalização dos conteúdos que configuram novos mapas de saberes (DUSSEL, 2014).

Por outro lado, em que pesem as desigualdades de acesso e o uso das TD pelas crianças, em razão da sua origem social e cultural, e as concepções de criança e infância expressas nos documentos curriculares, mesmo pautadas em um certo determinismo tecnológico, parecem apontar uma possibilidade para a mudança no papel da criança na escola, deixando de ser apenas um receptor passivo do conhecimento definido exclusivamente pelo professor. Essa possibilidade coloca-se de forma ambivalente, uma vez que o domínio das competências digitais pelas crianças parece torná-las particularmente mais capazes de moverem-se na "sociedade do conhecimento" e, ao mesmo tempo, com acesso livre à informação (via internet), inclusive aos conteúdos tradicionalmente reservados aos adultos, a acrescido ao caráter lúdico com o qual as crianças significam a utilização das tecnologias aponta para a ameaça da perda do seu estatuto de crianças. "A hipervalorização das competências infantis vai a par 
da diabolização das próprias crianças, face à 'perda da inocência' que as tecnologias presumivelmente propiciam." (SARMENTO, 2011, p. 599, grifo do autor).

Além disso, o conhecimento, também redimensionado pela participação ativa das crianças na escola, poderia converter-se no "conhecimento poderoso", "[...] conhecimento que, para a maioria delas, não poderia ser adquirido em casa ou em sua comunidade.” (YOUNG, 2007, p. 1294). Eis algumas questões que precisam ser consideradas e que também podem iluminar esse debate.

Notas explicativas:

${ }^{1}$ Nesta pesquisa, optamos pelo uso da expressão tecnologia digital, pois entendemos que são os recursos mais presentes nos programas de inserção de tecnologia nas escolas. De acordo com Amaral (2011), a tecnologia digital refere-se à convergência digital do vídeo, textos e gráficos. Significa, portanto, uma nova materialidade das imagens, textos e sons que, na memória do computador, estão definidos matematicamente e processados por algoritmos em combinações numéricas de 0 ou 1 .

2 Relatório de pesquisa realizado pelo Comitê Gestor da Internet no Brasil (CGI.br), que mapeou os impactos sociais das TICs e a inclusão digital em crianças de 5 a 9 anos no Brasil.

${ }^{3}$ Relatório de pesquisa realizado pelo Comitê Gestor da Internet no Brasil (CGI.br), que objetivou mapear as oportunidades e os riscos associados ao uso da internet em crianças e adolescentes brasileiros de 9 a 16 anos de idade.

4 Optamos por não utilizar o Parecer do CNE/CP n. 2/2015 e a Resolução do CNE/CP n. 2/2015, que definem as novas Diretrizes Curriculares Nacionais para a formação inicial em nível superior (cursos de licenciatura, cursos de formação pedagógica para graduados e cursos de segunda licenciatura) e para a formação continuada, por se tratarem de documentos recentes e que ainda não impactaram os projetos de cursos e redes de ensino, necessitando, assim, uma análise mais pormenorizada das semelhanças e das diferenças no modo como o discurso de TD é abordado em ambos os documentos, o que não teríamos condições de abordar nos limites deste artigo.

\section{REFERENCIAS}

AMARAL, S. F. do. Principios y reflexiones del lenguaje digital interactivo. In: AMARAL, S. F.; SOUZA, M. I. F. (Org.). TV digital na educação: contribuições inovadoras. Campinas: FE/Unicamp, 2011.

BALL, S. Educational reform: a critical and poststructural approach. Buckingham: Open University Press, 1997.

BARRETO, R. G. Tecnologia e educação: trabalho e formação docente. Educação \& Sociedade, Campinas, v. 25, n. 89, p. 1181-1201, set./dez. 2004.

BERNSTEIN, B. A estruturação do discurso pedagógico: classe, códigos e controle. Petrópolis: Vozes, 1996. 
BRASIL. Conselho Nacional de Educação. Parecer n. 9/2001. Diretrizes Curriculares Nacionais para a Formação de Professores da Educação Básica, em nível superior, curso de licenciatura, de graduação plena. Diário Oficial da União, Brasília, DF, 08 maio 2001. Disponível em: <http://portal.mec.gov.br/cne/arquivos/pdf/009. pdf>. Acesso em: 20 maio 2016.

BRASIL. Conselho Nacional de Educação. Resolução n. 1, de 18 de fevereiro de 2002. Institui Diretrizes Curriculares Nacionais para a Formação de Professores da Educação Básica, em nível superior, curso de licenciatura, de graduação plena. Diário Oficial da União, Brasília, DF, 09 abr. 2002.

BRASIL. Ministério da Educação. Secretaria de Educação Básica. Diretoria de Currículos e Educação Integral. Diretrizes Curriculares Nacionais Gerais da Educação Básica. Brasília, DF: MEC, SEB, DICEI, 2013. Disponível em: <http:// portal.mec.gov.br/index.php?option=com_docman\&view=download\&alias $=15547$ -diretrizes-curiculares-nacionais-2013-pdf-1\&Itemid=30192>. Acesso em: 30 ago. 2016.

BUCKINGHAM, D. Repensando a criança-consumidora: novas práticas, novos paradigmas. Comunicação, mídia e consumo, São Paulo, v. 9, n. 25, p. 43-72, ago. 2012. Disponível em: <http://revistacmc.espm.br/index.php/revistacmc/article/ view/311/pdf>. Acesso em: 04 fev. 2016.

COMITE GESTOR DA INTERNET NO BRASIL. Pesquisa sobre o uso de tecnologias de informação e comunicação no Brasil: TIC Crianças 2010. São Paulo, 2012.

COMITÊ GESTOR DA INTERNET NO BRASIL. TIC kids online Brasil 2012: pesquisa sobre o uso da internet por crianças e adolescentes. São Paulo, 2013.

COMITÊ GESTOR DA INTERNET NO BRASIL. TIC kids online Brasil 2013: pesquisa sobre o uso da internet por crianças e adolescentes. São Paulo, 2014.

DUSSEL, I. Es el curriculum relevante en la cultura digital? Debates y desafíos sobre la autoridad cultural contemporánea. Archivos Analíticos de Políticas Educativas, Tempe, v. 22, n. 24, p. 1-26, 2014. Disponível em: <http://www.redalyc.org/ articulo.oa? id=275031898046>. Acesso em: 05 mar. 2016.

DUSSEL, I. Más allá del mito de los “nativos digitales”. Jóvenes, escuelas y saberes en la cultura digital. In: SOUTHWELL, M. (Comp.). Entre generaciones. Exploraciones sobre educación, cultura e instituciones. Rosario: FLACSO/Homo Sapiens, 2012. p. 183-213.

ESTEVES, J. M. O mal-estar docente: a sala de aula e a saúde dos professores. São Paulo: EDUSC, 1999. 
FOUCAULT, M. Vigiar e punir. 10. ed. Petrópolis: Vozes, 1993.

MONTANDON, C. Sociologia da infância: balanço dos trabalhos em língua inglesa. Cadernos de Pesquisa, São Paulo, n. 112, p. 33-60, mar. 2001.

PACHECO, J. A. Políticas curriculares: referenciais para análise. Porto Alegre: Artmed, 2003.

PINTO, M. “A infância como construção social”. In: PINTO, M.; SARMENTO, M. J. (Org.). As crianças: contextos e identidades. Braga, Portugal: Universidade do Minho - Centro de Estudos da Criança, 1997. p. 31-74.

PONTE, C.; SIMÕES, J. A. Comparando resultados sobre acessos e usos da Internet: Brasil, Portugal e Europa. In: CGI.br. TIC kids online Brasil 2012 [livro eletrônico]: pesquisa sobre o uso da Internet por crianças e adolescentes. Coordenação executiva e editorial Alexandre F. Barbosa. São Paulo: Comitê Gestor da Internet no Brasil, 2013. p. 27-36.

PRENSKY, M. Digital natives, digital immigrants. On the Horizon, v. 9, n. 5, p. 1-16, out. 2001. Disponível em: <http://www.marcprensky.com/writing/Prensky\%20-\%20Digital\%20Natives, \%20Digital\%20Immigrants\%20-\%20Part1.pdf $>$. Acesso em: 02 fev. 2016.

QVORTRUP, J. A infância enquanto categoria estrutural. Educação e Pesquisa, São Paulo, v. 36, n. 2, p. 631-644, maio/ago. 2010a. Disponível em: $<$ http://www.scielo. br/pdf/ep/v36n2/a14v36n2.pdf>. Acesso em: 10 maio 2016.

QVORTRUP, J. Infância e política. Cadernos de Pesquisa, São Paulo, v. 40, n. 141, p. 777-792, dez. 2010b. Disponível em: <http://www.scielo.br/pdf/cp/v40n141/ v40n141a06.pdf>. Acesso em: 10 maio 2016.

SARMENTO, M. J. A reinvenção do ofício de criança e de aluno. Atos de Pesquisa em Educação, Blumenau, v. 6, n. 3, p. 562-571, 2011. Disponível em: <http://proxy. furb.br/ojs/index.php/atosdepesquisa/article/view/2819/1825>. Acesso em: 10 maio 2016.

SARMENTO, M. J. As culturas da infância nas encruzilhadas da $\mathbf{2}^{\mathbf{a}}$ modernidade. 2002. Disponível em: <http:www.iec.minho.pt/cedic/textos de trabalho>. Acesso em: 22 maio 2016.

SARMENTO, M. J.; PINTO, M. Introdução: as crianças e a infância: definindo conceitos, delimitando o campo. In: PINTO, M.; SARMENTO, M. J. (Org.). As crianças: contextos e identidades. Braga, Portugal: Universidade do Minho - Centro de Estudos da Criança, 1997. p. 9-30. 
SELWYN, N. The digital native: myth and reality. Aslib Proceedings, v. 61, n. 4, p. 364-379, 2009. Disponível em: <http://dx.doi.org/10.1108/00012530910973776>. Acesso em: 10 maio 2016.

SIROTA, R. Emergência de uma sociologia da infância: evolução do objeto e do olhar. Cadernos de Pesquisa, São Paulo, n. 112, p. 7-31, mar. 2001. Disponível em: $<$ http://www.scielo.br/pdf/cp/n112/16099.pdf >. Acesso em: 04 jan. 2016.

SOSSAI, F. C.; SILVA, G. M.; LUNARDI-MENDES, G. M. Programa Um Computador por Aluno em escolas públicas de Santa Catarina: notas sobre a sedução contemporânea por tudo digitalizar. E-tech: Tecnologias para Competitividade Industrial, p. 71-81, 2012. Edição especial. Disponível em: <http://revista.ctai.senai. br/index.php/edicao01/article/view/299>. Acesso em: 10 maio 2016.

SOUZA, R. F. de. Objetos de ensino: a renovação pedagógica e material da escola primária no Brasil, no século XX. Educar em Revista, Curitiba, n. 49, p. 103-120, jul./set. 2013. Disponível em: <http://www.scielo.br/pdf/er/n49/a07n49.pdf>. Acesso em: 04 maio 2016.

VIEIRA PINTO, Á. O conceito de tecnologia. Rio de Janeiro: Contraponto, 2005.

YOUNG, M. Para que servem as escolas? Educação \& Sociedade, Campinas, v. 28, n. 101, p. 1287-1302, set./dez. 2007. Disponível em: <http:/www.scielo.br/pdf/es/ v28n101/a0228101.pdf>. Acesso em: 10 maio 2016.

Recebido em: 03 de julho de 2016

Aceito em: 07 de setembro de 2016

Endereço para correspondência: Rua João David Ferreira Lima, Trindade, 88040900, Florianópolis, Santa Catarina, Brasil; carlacrisloureiro@gmail.com 